\title{
Negatividad y recepción estética: Las emociones difíciles a la luz del pensamiento dialéctico de Adorno ${ }^{1}$
}

\author{
Negativity and Aesthetic Reception: \\ Difficult Emotions in Light of Adorno's \\ Dialectical Thought
}

\author{
MARÍA JESÚS GODOY DOMÍNGUEZ \\ Universidad de Sevilla
}

Recibido: 05/06/2017 Aceptado:02/10/2017

\begin{abstract}
RESUMEN
El concepto de negatividad recorre el pensamiento dialéctico de Adorno en su intención de rebatir u oponerse a lo establecido, de rescatar del sometimiento y el olvido a las víctimas de cualquier voluntad de dominio. Este deseo de recuperación se asocia aquí al restablecimiento de las emociones negativas en la reflexión estética anglosajona actual, en especial el asco, que despreciado en la tradición estética moderna en nombre del placer, permite advertir una voluntad de dominio similar a la denunciada por Adorno y un enfoque dialéctico análogo al suyo también, en la reciente pretensión de devolverle a este afecto su dignidad.
\end{abstract}

PALABRAS CLAVE

DIALÉCTICA, NEGATIVIDAD, ADORNO, EMOCIONES NEGATIVAS, ESTÉTICA MODERNA

1 Una versión simplificada de este trabajo fue presentada como comunicación en el encuentro «No Art without Politics. Exchanges between Deconstruction and Critical Theory», celebrado en la Universidad de Barcelona y el Centro Arts Santa Mònica, los días 11 y 12 de mayo de 2017.

(C) Contrastes. Revista Internacional de Filosofía, vol. XXIII-Nº1 (2018), pp. 111-126. ISSN: 1136-4076

Departamento de Filosofía, Universidad de Málaga, Facultad de Filosofía y Letras

Campus de Teatinos, E-29071 Málaga (España) 


\section{ABSTRACT}

The concept of negativity runs through Adorno's dialectical thinking in his intention to refute or oppose the establishment, to rescue the victims of any will of dominance from submission and oblivion. This desire for recovery is related here to the rehabilitation of negative emotions in contemporary aesthetic reflection. This is the case of disgust, which despised in modern aesthetic tradition in the name of pleasure, allows us to notice a will of dominance analogous to that denounced by Adorno. Indeed, both emotions, disgust and pleasure, have been recently approached from a similar dialectic position thus conferring dignity to the former.

KEYWORDS

DIALECTICS, NEGATIVITY, ADORNO, NEGATIVE EMOTIONS, MODERN AESTHETICS

ESTE TRABAJO SE ARTICULA EN TORNO al concepto de negatividad y sus derivados, en el sentido, por un lado, de no admitir la verdad o existencia de algo en lo que otro cree o afirma, como sinónimo entonces de contradecir, rebatir u oponerse -sería el caso de los términos negar, negativo o negación-; y en el sentido, por otro lado, de no acceder a lo que alguien pretende o solicita $\mathrm{y}$, por tanto, como prohibir, desestimar o rechazar -que es lo que significan, a su vez, los vocablos denegar, negativa y denegación-; dos sentidos aquí estrechamente interconectados, como procedemos a explicar.

\section{PEnSAMiento Negativo}

De entrada, el primero de ellos nos remite directamente a Adorno, no tanto en una obra en particular, como en el corpus general de su pensamiento, pues la idea de objetar, rebatir e impugnar -a la que hemos asociado el primer sentidorecorre a éste de arriba abajo como su principal seña de identidad. Si por algo puede decirse, en efecto, que los planteamientos estéticos y filosóficos de Adorno son negativos o tienen en la negación su herramienta básica (Álvarez López 2000, p. 44) es por su componente crítico, por la revisión que pretenden y, de hecho, llevan a cabo, de lo establecido: del proyecto ilustrado, de la sociedad burguesa, de la cultura de masas, del arte o también, y en especial para nuestro interés aquí, del esquema dialéctico hegeliano -de atentado contra la tradición, califica a este respecto su acción el propio filósofo ${ }^{2}$-. Este esquema, hay que recordar, era un esquema de diálogo entre opuestos que acababa indefectiblemente en una síntesis conciliadora, síntesis orientada así a superar precisamente la negatividad de partida -ya que entre dos opuestos, uno es siempre y necesariamente la negación o el negativo del otro, la antítesis

2 Las palabras exactas que sirven de pórtico a su Dialéctica negativa son: «La formulación dialéctica negativa atenta contra la tradición. Ya en Platón, la dialéctica quiere obtener algo positivo mediante el instrumento intelectual de la negación; más tarde, la figura de una negación de la negación designó esto lacónicamente. Este libro querría liberar a la dialéctica de semejante esencia afirmativa [...]» (Adorno 2005, p. 9). 
lo es siempre respecto a una tesis inicial- y a cerrar por eso la rivalidad o el antagonismo en positivo. Con esta fiscalización del sistema filosófico heredado de Hegel, ${ }^{3}$ Adorno quiso hacer efectiva la variedad y pluralidad intrínsecas al concepto mismo de «reconciliación», frente a la lógica únivoca, reductivista y simplificante que, en su opinión, venía presidiéndolo. Es más, intentó sacar a la luz la falta realmente de acuerdo, el mantenimiento de la discordia y escisión subyacentes a esa presunta armonía, que nunca fue tal desde el momento en que fue alcanzada a costa de uno de los polos o extremos implicados, que reducido en el fondo al otro, único reconocido como legítimo y verdadero, y llevando así las de perder, fue anulado, sometido, humillado, negado en última instancia -en el segundo sentido de la negatividad antes señalado, el de mancillar y despreciar, presente así también en nuestro pensador-. Este polo o extremo serviría, en todo caso, para demostrar lo lejos que estaba en realidad aquel supuesto convenio de toda neutralidad y equidistancia, y lo engañoso y fraudulento que por consiguiente era.

La negatividad intrínseca a las tesis de Adorno se relaciona estrechamente, pues, con la dialéctica de la Ilustración que teorizara el filósofo junto a su compañero de filas Horkheimer y, por ende, con el propósito de rechazar la voluntad de dominio en cualquiera de sus manifestaciones: en la filosófica, en primer lugar, que él veía materializada ante todo en el idealismo de Hegel en tanto «pensamiento de la identidad» (Adorno 2005, p. 480), pero después también en su expresión social y objetiva, pues la metafísica hegeliana de la identidad se concretó, ciertamente, en una sociedad que todo lo identificaba y homogeneizaba, al tiempo que reprimía también todo cuanto la negaba, que ocultaba aquello que se resistía a dicha unificación y descartaba así lo heterogéneo, lo singular, lo divergente o lo simplemente negativo para aquel mecanismo dinámico-histórico de abstracción (Zamora 2004, pp. 187-192). Este «sistema del horror», en definición del propio Adorno (2006, p. 118), ha llegado a ser característico, sin ir más lejos, de la sociedad capitalista, que como sociedad racional de inspiración ilustrada, exalta al individuo a la vez, sin embargo, que lo anula -lo niega, impide su existencia, en el segundo sentido de la negatividad-, pues anuladas -negadas- resultan igualmente su particularidad y su diferencia, su autonomía, por efecto de la uniformidad que impone el nuevo sistema de producción industrial y consumo masivo, el mundo administrado, en definitiva, donde hoy por hoy vivimos. ${ }^{4}$ En otras

3 Vicente Gómez habla, a propósito de ello, de «estricto ajuste de cuentas con Hegel» (1998, p. 89).

4 Adorno sostiene, en este sentido y explícitamente, que la sociedad «es tanto una suma de sujetos como la negación de éstos» porque «están en ella irreconocibles y desvigorizados» (Adorno 2005, pp. 21-22). 
palabras, que el mismo ordenamiento constituido, en el plano teórico, en torno al individuo y su libertad acaba, paradójicamente, desindividualizándolo y sometiéndolo en el plano real -circunstancia que conocería su versión más canallesca y cruel en el Holocausto judío, «la negatividad absoluta» para Adorno (2005, p. 332) - $^{5}$, frustrando así toda esperanza de felicidad. Y lo peor es que esa desviación de los ideales ilustrados no es algo sobrevenido de repente a la cultura tardocapitalista, nuestra cultura, sino la expresión de su propia naturaleza totalitaria, aunque encubierta -eso sí- bajo la falsa ideología de la libertad.

No obstante y pese a que el individuo, hemos dicho, ha sido convertido en el soporte ideológico del actual sistema de dominio -se nos invita a ser nosotros mismos, a diferenciarnos, en una sociedad que ha acabado, sin embargo, por volvernos a todos iguales y estandarizados-, para Adorno la esperanza seguiría residiendo, después de todo, en la individualidad, en la afirmación de las diferencias particulares que nunca debieron ser sacrificadas en aras del todo social. ${ }^{6}$ Esa totalidad, conseguida a base de reducir a sus miembros conformantes a un denominador común, de compactarlos en un solo bloque, sería entendida así como «lo no verdadero» (Adorno 2006, p. 55), pues la verdad, desde este enfoque, donde se hallaba era en la parte, en el fragmento, en lo arrancado y desjagado del sistema que sin ser aprehendido por él, no llegaba a ser identificado ni disponía de sentido, pero tampoco era sometido o inhabilitado - no era negado, según hemos visto-. Por tanto, como comprender y racionalizar lo no-idéntico, conceptualizarlo de acuerdo a la dialéctica hegeliana y al ordenamiento social emanado de ella, suponía ratificar su modo opresivo de actuar y cometer por eso una injusticia con aquello que se salía de sus parámetros universalizantes, Adorno acabó rebelándose contra toda praxis conciliadora y diseñando una nueva dialéctica, negativa y material por oposición a la positiva e idealista -fallida en todo caso (Gómez 1998, pp. 18 y 89)- legada por Hegel. Era la dialéctica con la que hacer aflorar la tensión oculta bajo aquella aparente concordia, con la que rescatar lo peculiar sofocado bajo el imperio de lo general y recuperar así lo otro que, diferente a lo mismo, veía reconocido al fin su derecho a la existencia y era afirmado; una dialéctica donde lo otro y lo mismo no sólo no se daban ya el uno sin el

5 Énfasis nuestro.

6 Esta defensa acérrima del individuo es lo que ha llevado a plantear recientemente la problemática de los derechos humanos en el pensamiento de Adorno, que sin ser una cuestión de primer orden dentro del mismo, sí sería abordada en forma de crítica dirigida a la instrumentalización, por parte de las sociedades capitalistas, de los supuestos ideológicos vertebradores de un discurso humanista -el discurso liberal propiamente democrático de las sociedades occidentales actuales- orientado precisamente a la defensa de los derechos y las libertades individuales. Véase Galé Argudo 2014. 
otro o sometiendo el uno al otro como hasta entonces, sino que se auxiliaban y completaban, estando como estaban al mismo nivel y, sobre todo, en contraste permanente; una dialéctica que resistiéndose a toda falsa unificación y rigidez, terminaba forzando a la identidad a abrazar la no-identidad; una dialéctica, en resumidas cuentas, que al hacerse negativa se volvía plenamente dialéctica.

Es importante destacar, a propósito de ello, que Adorno asumió casi como un imperativo ético -imperativo inmanente y ligado a la experiencia, frente al trascendente, abstracto e intemporal de ascendencia kantiana- la recuperación y la memoria, que en el conjunto de sus propuestas es lo que vendría a resolver el problema de la síntesis hegeliana (Tafalla 2003, pp. 48 y ss). Lejos de plantearse a la manera de aquella tercera y última fase con la que se cerraba la dialéctica clásica, la que suponía dejar atrás la crisis inicial y, de ese modo, avanzar, pero a fuerza de domeñar, de omitir el dolor de quienes se veían con ello perjudicados, la recuperación y la memoria se presentaban, en cambio, como un nuevo tipo de solución, pues desechando la pretensión de totalidad y de sistema cerrado, encerraban en sí mismas un gran potencial reparador. El motivo es el siguiente: abriéndose a lo dinámico y discontinuo, a lo inacabado, la memoria significaba, por un lado, la exhumación del pasado como forma de dar visibilidad a todos los que padecieron esa suerte de atropello y restablecer así su honor y dignidad; por otro lado, aparejaba también la convicción de que es imposible construir un presente estable o esperar un futuro mejor-liberado, en todo caso, de los errores cometidos- sin reconocer en toda su amplitud el sufrimiento de quienes fueron víctimas, la convicción al fin y al cabo de que no hay progreso sin un cierto retroceso, esto es, sin un examen de conciencia, una reparación de daños, un mea culpa por parte de los verdugos y, de ese modo, una reformulación en toda regla de la verdad histórica, del relato que éstos interesadamente dieron a conocer y que sin duda les favorecía.

El elemento clave de esta otra construcción dialéctica y de la razón anamnética sobre la que ella descansaba era el arte, porque el arte, afirmaba Adorno apoyándose en Schopenhauer, es «el mundo por segunda vez» (Adorno 2004, p. 187), pero no como simple duplicado estético del primero, o mera imago mundi, sino como mucho más: en tanto lugar de transgresiones, el arte era y es algo diferente de lo ya conocido, de la sociedad contemporánea y su uso instrumental de la razón (Adorno y Horkheimer 2001). Es en realidad el negativo de ese primer mundo, dada su capacidad para transformarlo en sentido crítico y polémico, y para recuperar aquello que fue borrado de la historia sin dejar rastro. De algún modo, el arte, partiendo del mundo empírico pero alejándose lo suficiente de él, en el ejercicio pleno de su autonomía, lo niega -en nuestro primer sentido-, o sea, niega la universalidad negadora -en el segundo- de las singularidades por la que dicho mundo se rige; es 
sencillamente negación de la negación. ${ }^{7}$ Por eso, para Adorno y en virtud del potencial subversivo que encierran, como acto de resistencia, «las obras de arte son negativas a priori» (Adorno 2004, p. 181) ${ }^{8} \mathrm{y}$, por eso, hay que comprenderlas también poniéndolas en relación inversa con la realidad sometedora a la que pertenecen y de la que brotan, contraponiéndolas a ella. Es lo que ocurre con el arte revolucionario, arte radical o arte negro (Gutiérrez Pozo 2007), el arte auténtico en la medida en que insufla vida a la dialéctica negativa-arte negativo, por tanto, y negativa asimismo la estética que lo piensa y estudia-; el arte que haciendo aflorar lo doliente y sangrante del sistema, la particularidad negada y de ese modo dañada en su seno, consigue «introducir caos en el orden» (Adorno 2006, p. 230). Y lo hace, porque dándole voz, haciendo hablar a ese sufrimiento, no sólo constituye un primer paso para aliviarlo, sino que en la senda además de la justicia y la verdad, le da la vuelta al sistema responsable de tan funesta situación y, por supuesto, a su versión sesgada y unilateral de lo ocurrido.

En efecto, bajo la forma de la disonancia y la desfiguración, forma negativa en todo caso -en música y pintura respectivamente, con Schönberg y Picasso por ejemplo-, el arte revolucionario pone patas arriba el sistema social de dominio en tanto pone patas arriba también los logros del arte conservador o arte colorista -el kistch sin más-; este otro arte, acomodado en dicho sistema, puesto a su servicio y de su afán totalizante, ayuda a maquillar sus heridas, a esconder lo negativo, a aparentar al fin y al cabo unidad donde lo que reina en verdad es una dispersión y desgregación atroces. Siendo entonces el arte revolucionario algo distinto de lo que es social y estéticamente, pero estando a la vez profundamente involucrado en ambas esferas por su denuncia de la dominación acometida desde ellas y su trabajo en favor del recuerdo, es promesse de bonheur. ${ }^{9}$ Es decir, el arte revolucionario se dota para Adorno de un importante trasfondo utópico - «el arte tiene que ser y quiere ser utopía»

7 Siguiendo a Christoph Menke, la diferencia aquí entre lo estético y lo no estético, lo que permite tomarle el pulso, en definitiva, a la autonomía estética, es precisamente la negatividad, la función crítica que se supone que ejerce el arte respecto a la realidad extra-artística y a la que Menke se refiere, basándose de Derrida, como soberanía (Menke 1997, pp. 23 y 189 y ss). Una actualización y mayor desarrollo de estas mismas tesis suyas pueden encontrarse en Menke 2011, pp. 37-67.

8 Énfasis nuestro.

9 Nos hacemos eco así y hacemos confluir dos de los cuatro sentidos señalados por Gerard Vilar para el arte auténtico de Adorno en tanto arte negativo: el de la relación crítica con la realidad, por un lado, y el de la relación crítica a través de su autonomía, por otro, esto es, como esfera independiente de validez que le permite poner en evidencia las miserias e insuficiencias de esa realidad. Ambas acepciones quedarían englobadas así dentro de lo que venimos considerando aquí primer sentido de la negatividad (Vilar 2015). 
escribe al respecto el representante de la Escuela de Frankfurt (Adorno 2004, p. 51)-, pues apuntando hacia lo que todavía no es pero puede llegar a ser, manteniendo la esperanza de un futuro alternativo frente al pasado y al presente, permite barruntar un mundo liberado al fin de la injusticia y la barbarie, también de la desmemoria y, por eso mismo, sin fracturas ni desgarramientos internos, sin víctimas, sin violencias y, de una vez por todas, sin sufrimiento. ${ }^{10}$

El arte radical adquiere, en este sentido, un valor ejemplar inigualable: es la mejor encarnación de la dialéctica adorniana, del decir no -negarse- a lo ya acontecido y del deseo de que nunca más vuelva a repetirse (Iriondo 2015, p. 50). Cuenta, para ello, con un antídoto infalible como es la emoción, la empatía hacia el otro humillado y sufriente, que es lo que queda plasmado en el terreno compositivo, lo que se cuenta artísticamente aunque de manera transfigurada -lo que se comunica desde la incomunicación, al decir de Adorno (2004, p. 272) ${ }^{11}$-, como sucede en el Guernica de Picasso, el Pierrot Lunaire de Schönberg o Mahagonny de Brecht. Este tipo de obras están pensadas para diluir el propio yo en el yo de otros y poder albergar así, en uno mismo imaginariamente, de manera subsidiaria o por delegación-, otras posibilidades identitarias; para viajar hasta aquellos otros que han sido ultrajados, pues sólo acogiendo como propio el dolor ajeno puede llegar a entenderse éste y pueden ponerse los medios para mitigarlo, para dejar constancia de él en la historia que quiso ocultarlo. Obras como las referidas nos hacen viajar hacia esos otros sujetos, penetrar en sus vidas para sufrir allí, en ellas, lo que ellos están sufriendo, experimentar su dolor -implicarnos así éticamente, en una primera dimensión más comprometida y heterónoma del arte-, pero conservando a la vez parte de nuestra identidad mientras nos desdoblamos -0 sea, aminorando la intensidad de la emoción sentida y dotándonos así de cierta distancia desde la que reaccionar juiciosamente a la situación, gracias a una segunda dimensión artística más autónoma-. Y es que, aun enajenándonos, aun saliendo de nosotros mismos para adherirnos a lo diferente, nuestro yo nunca desaparece del todo, ${ }^{12}$ por lo que acabamos tomando conciencia de las

10 Componente utópico relacionado así con el utopismo soñador y melancólico, típico de las diferentes ideologías de izquierdas y basado como en Adorno en la redención de las víctimas de la historia frente a la cultura de los señores. Ver Retamal 2016.

11 En palabras textuales de Adorno: «La paradoja de que el arte lo dice y no lo dice se debe a que eso mimético mediante lo cual lo dice es opaco y particular, por lo que al mismo tiempo se opone a decirlo».

12 La experiencia es por eso la contraria, según el filósofo, a la del debilitamiento del yo por parte de la industria cultural (Adorno 2004, p. 323). 
circunstancias de fondo que motivan esa identificación y, lo más importante de cara al futuro, nos vemos llamados a actuar para ponerles cuanto antes remedio. $^{13}$

\section{EMOCIONES NEGATIVAS Y NEGADAS}

Si el primer sentido de la negatividad nos ha llevado, en primer lugar, hasta Adorno, el segundo nos conduce ahora hasta las emociones negativas -en las que, como veremos, está presente también el primero, al igual que en Adorno hemos visto que está contenido asimismo el segundo sentido-. Estas emociones son las consideradas tradicionalmente así por su naturaleza incómoda y desagradable, como ocurre con la pena, el miedo, el enfado, la indignación y, por supuesto, el asco, que desde este enfoque, es el negativo entre los afectos negativos, el negativo por definición, ya que la incomodidad y el desagrado llega en su caso a sus máximas cotas. Si una cosa ha quedado clara de la negatividad dialéctica de Adorno es que algo es negativo -en el primer sentido analizado- en tanto niega, rebate o se opone a algo tenido a su vez por positivo y con lo que mantiene una discrepancia que el esquema dialéctico clásico -el hegeliano, claro- ha intentado siempre solucionar estableciendo un supuesto equilibrio de fuerzas entre ellos; no así la dialéctica de Adorno, que instalada, en cambio, en la tensión y el desacuerdo, en el juego de antagonismos sin el que es imposible entender el propio concepto de dialéctica, ha denunciado la falsedad de esa medida, argumentando que en realidad escondía una clara asimetría, que en todos los casos existía, más o menos encubiertamente, un vencedor y un vencido. Trasladando esta visión general al supuesto concreto de las emociones, resulta que las negativas han venido siéndolo estrictamente como anverso histórico de las positivas, es decir, como emociones dolorosas en tanto contrapuestas a las placenteras, con las que nunca estuvieron en pie de igualdad. La responsable de esta descompensación de fuerzas fue, sin duda, la estética moderna, que a la hora de domiciliar el juicio de gusto en la interioridad subjetiva, premió el placer - o sea, lo identificó con él, dicho en términos de la metafísica hegeliana de la identidad- y castigó, en cambio, el dolor -al que relegó de ese modo a lo noidéntico y diferente y, por extensión, a lo despreciable-. En resumidas cuentas, que las emociones negativas fueron derrotadas, en tanto no-placenteras, en

13 Este alejamiento final y la consiguiente incitación a la actividad es lo que distingue a juicio de Adorno -y de la reflexión estética contemporánea en general que arranca en Edward Bullough en 1912 (1957)- la experiencia estética en el caso del verdadero arte, el de las vanguardias, de la experiencia en el caso del pseudo-arte, arte engañoso o directamente no-arte, esto es, el arte de masas, arte colaboracionista o kitsch, arte incapaz, en cambio, de deshacerse de la adhesión afectiva y de la contemplación pasiva subsiguiente. 
el momento de instituirse la experiencia estética moderna, lo que a la larga supuso desterrarlas como respuesta válida y legítima al arte.

Ahora bien, esto sería según el relato oficioso de hechos, elaborado y resumido aquí conforme a los presupuestos dialécticos de Adorno, porque en el relato oficial, el de los vencedores -del que además hubo dos versiones principales, como veremos a continuación- las cosas fueron bien distintas: los afectos dolorosos, cuando tomaban parte de la experiencia estética -algo que sucedía de tarde en tarde-, lo hacían siempre coexistiendo en paz con los placenteros. Lejos de haber entonces ningún enfrentamiento o animadversión entre ellos, se entendían a la perfección, siendo todo un modelo así de síntesis hegeliana, como lo era, sobre todas las cosas, la experiencia estética de lo sublime. Según Burke primero (2000) y Kant después (2001, § 23-29), esta experiencia constaba de un primer momento afectivo ciertamente doloroso, de miedo exactamente, que estaba provocado por el objeto de magnitud inconmensurable al que se enfrentaba el sujeto. Éste, reducido con ello prácticamente a la nada, era capaz de sobreponerse, sin embargo, rápidamente al descubrir esa misma magnitud, ya no física, sino racional y moral, en su propia interioridad. Ello generaba un segundo momento, superpuesto y casi confundido con el primero, placentero por el contrario y muy confortable, fruto de ese conocimiento. En la versión dominante de hechos basada en la conversión -en la que junto al propio Burke, figura otro pensador como Hume, lo que sucedía en esta experiencia era que la emoción negativa inicial «se convertía» en positiva - de ahí su nombre- en el curso de la apreciación estética, por lo que el dolor terminaba reconciliándose con el disfrute, que era al fin y al cabo lo importante. En la versión basada, en cambio, en la compensación -la de Dubos y Diderot, por ejemplo-, la emoción positiva final reparaba o, de algún modo, «compensaba»-explicándose así esta otra denominación- el efecto desapacible del primer instante, pero siendo el resultado en todo caso el mismo, el restablecimiento final del equilibrio. ${ }^{14}$

Aunque en el contexto aún de la estética pre-moderna, otro ejemplo de síntesis dialéctica a lo Hegel era la tragedia, donde según la antigua teorización aristótelica, el espectador empezaba siendo presa también de emociones adversas, como eran aquí la pena o lástima y el miedo, provocados por su identificación empática con los personajes que veía sufrir en escena -Antígona, Edipo u Orestes, por ejemplo-, si bien terminaba sintiendo gratamente; sentía un gran alivio en realidad, o liberación catártica, en términos del propio Aristóteles, al comprender que era sobre ese otro ficticio y no sobre él mismo, como sujeto real, sobre quien recaía el mal causante

14 Para ambas explicaciones a la llamada «paradoja de la tragedia» dentro de la reciente literatura estética, véase Levinson 2015. 
del sufrimiento. ${ }^{15}$ Nuevamente, pues, la afección negativa era convertida o reparada por la positiva que iba detrás y que era la que recomponía, en último extremo, el orden de partida, la que devolvía sin demora al statu quo.

Aplicando, sin embargo, el enfoque subversivo y contrafáctico de Adorno, su deseo de articular la crónica de los vencidos, lo que ocurría en verdad en lo sublime y lo trágico era que el displacer era redimido por el placer y, de esa forma, neutralizado y reducido a él. No podía ser de otro modo además, teniendo en cuenta el enorme recelo con el que desde siempre se ha mirado a estos estados emocionales, cuya existencia quedaba así controlada, por no decir que era rechazada, que es como era en realidad, pues por medio del placer, el displacer era negado, o mejor, denegado, lo que significa-según, una vez más, la segunda acepción de la negatividad que venimos manejandoque quedaba absolutamente descartado como respuesta afectiva al arte. Esto es, ni más ni menos, lo que intenta poner de relieve el relato alternativo de hechos, que alejado de fraudulentas reconciliaciones como en Adorno y con miras dialécticas similares a las suyas, se ha venido esbozando en los últimos tiempos en torno a las emociones negativas, a fin de restituirles el valor estético que nunca debieron perder y rescatarlas así de los márgenes de la historia, de su olvido habitual. ${ }^{16}$ De esta narración a contrapelo,${ }^{17}$ nos interesa sobre todo el capítulo dedicado al asco, que de la mano de Carolyn Korsmeyer (2011),

15 En la Poética, aconseja, en efecto, Aristóteles construir el argumento de la tragedia de modo que sean esas dos emociones precisamente -la pena y el miedo- las que entren en juego y se despierten en el espectador en su capacidad de generar placer a través de su representación artística (1453b3-13).

16 Las miras dialécticas de este otro relato son similares a las de Adorno y, más próximo aún a nosotros, a las de Jacques Rancière. La reflexión estética de este pensador francés, cuestionando los valores de autonomía y especificidad empleados para ahormar la estética y el arte en la modernidad -los relatos moderno y modernista respectivamente-, ha sabido conjugar en nuestros días la revisión de la historia del arte moderno con la autocomprensión de la propia estética. Gracias a ello y disintiendo de la tenida por «visión consensual» (Rancière 2005, p. 75), Rancière ha emprendido una reescritura de la modernidad artística, centrada en microrrelatos históricos, pequeños cuadros o escenas (Rancière 2014a), con el fin de darle un enfoque mucho más abierto, inclusivo y plural a las grandes narraciones en el ámbito tanto artístico como estético. Eso le ha llevado a fijarse, entre otras cosas, en el diseño y el papel tan destacado que, a su modo de ver, jugó éste en las transformaciones de lo estético y lo artístico, de lo sensible a fin de cuentas, en el paso del siglo XIX al XX: «[...] es en la teorización de las artes aplicadas donde hay que buscar la génesis de las fórmulas que servirán para emblematizar la autonomía del arte» (Rancière 2014a, p. 180).

17 Acudiendo de nuevo a Rancière, hablaríamos mejor de «contra-historia», que es el término que para este filósofo define realmente el replanteamiento y la deslegitimación de las «numerosas historias imaginarias de la modernidad artística» (Rancière 2014b, p. 27). 
representa el primer esfuerzo real, desde el establecimiento de la estética moderna, por dignificar el más denostado de los afectos, el más sufriente por tanto - prueba de ello es que Kant lo excluyó expresamente de la experiencia estética (2001, § 48)- y el que por eso mismo destapa, como ningún otro, la crisis no resuelta, o resuelta en falso -desde la óptica adorniana- del relato dominante. El apelativo de «organicista» por el que se conoce a esta versión heterodoxa de la experiencia estética moderna informa claramente ya del avance que supone respecto a la versión ortodoxa (Levinson 2015, p. 68): es organicista en tanto en cuanto la emoción negativa constituye en su caso un elemento imprescindible dentro de la experiencia de conjunto o del todo orgánico donde se integra, que precisamente por eso se aprecia, se valora y se desea en sí misma, tal cual, en su negatividad intrínseca. A la manera, por tanto, de Adorno -y de conformidad, dicho sea de paso, con nuestro primer sentido de la negatividad-, Korsmeyer se decanta también por la fricción y el desencuentro, por el litigio, para que la emoción fastidiosa no resulte en ninguna circunstancia absorbida por el disfrute, para que no sea sacrificada en su nombre -como sucede, por el contrario, en las versiones oficiales de la conversión y compensación respectivamente ${ }^{18}$ - y siga conservando así todo el desagrado que la caracteriza y la define ${ }^{19}$.

Pero lo sorprendente de ello -y aquí es donde empieza a notarse realmente el entronque de la posición dialéctica de Korsmeyer con la de Adorno- es que, sin perder un ápice de su negatividad, no por ello la emoción negativa vuelve negativa asimismo la experiencia estética donde se presenta; al revés, la insatisfacción que provoca tiene la virtud de volverla positiva, tanto o más incluso que cuando va unida al placer, lo que significa desposeer definitivamente a este afecto de la connotación peyorativa que históricamente ha venido arrastrando ${ }^{20}$. El motivo que aduce Korsmeyer no deja lugar a la duda: la experiencia desapacible de la repugnancia, aparte de una experiencia desde luego afectiva, es una experiencia también de índole cognoscitiva,

18 En ellas, según la autora, se desnaturaliza la emoción negativa y se vuelve positiva ,de la misma manera que se pinta la pared donde hay un graffiti incómodo: «If they are so strongly tinctured as totally to alter their nature, emotions such as fear and indignation-let alone disgust- are no longer part of the response to art. Such an outcome just removes the emotion from awareness in the way that one might paint over rude graffiti» (Korsmeyer 2011, p. 161).

19 Korsmeyer es rotunda al respecto: «In other words, disgust is the one emotion that cannot be transformed by means of art into an experience of beauty» (Korsmeyer 2011, p. 159). En realidad, es una idea que se repite una y otra vez a lo largo de su discurso: «(...) when disgust is aroused by art it often stays disgusting» (p. 87).

20 «The arousal of disgust often has a positive value in appreciation and understanding of artworks» (Korsmeyer 2011, p. 11). 
por lo que apareja un conocimiento que sin ella nunca se daría; ${ }^{21}$ de algún modo, pues, el asco, siendo como es una sensación extremadamente física, que remueve el estómago, incluso lleva a la náusea, permite tomar conciencia de realidades que de no ser así nos serían arrebatas, quedarían en la sombra o serían directamente olvidadas - negadas, para nosotros-, como sabemos que ocurre en la sociedad administrada de Adorno, sociedad aparentemente liberal, pero en el fondo -ocultándolo bajo esa supuesta libertad- sumamente represiva. Esas realidades a las que remite indefectiblemente la experiencia cognoscitiva del asco tienen que ver, según la autora, con nuestro destino final, como organismos vivos que somos, de muerte primero y descomposición y podredumbre posterior (Korsmeyer 2011, pp. 122-124). Desde el arte, la experiencia negativa del asco nos recuerda e invita a reflexionar sobre esa verdad terrible de la existencia, que es comunicada así con toda su crudeza, como con toda su crudeza y aspereza se manifiesta también el afecto conducente hasta ella: doloroso y desabrido es el mensaje a transmitir, y dolorosa y desabrida es igualmente la emoción de la que valerse desde el punto de vista receptivo para lograrlo. No sólo no hay entonces derrota o redención del afecto, como cabía esperar en los relatos vencedores, sino que se extrema su poder devastador, su capacidad de provocar descontento, como ocurría, hemos visto ya, con el arte radical de Adorno; un arte que desligándose del placer tradicional por falso e indecente, porque suponía participar del mismo sistema responsable de la anulación y cosificación del sujeto, pretendía hacerse cargo, en tanto eje vertebrador del relato de los vencidos y olvidados, de todo el dolor social que ello causaba -era, en ese sentido, «eco del sufrimiento» (Adorno 2004, p. $59)^{22}$-, si bien acallado por problemático, desafiante y perturbador.

Al igual que el arte revolucionario de Adorno, arte negativo y doliente, el arte susceptible de causar repugnancia de Korsmeyer se dota, pues, de un serio contenido de fondo, ético para ser exactos, al que sólo es posible acceder, sin embargo, mediante la dificultad de su apreciación. Teniendo en cuenta entonces que el conocimiento de ciertas realidades de la vida es estéticamente dependiente de formas irritantes de recepción, este tipo de experiencias resultan intrínsecamente valiosas y, por extensión, positivas, como lo es el arte radical para Adorno; ${ }^{23}$ pero -hay que fijarse bien- positivas

21 Como viene insistiéndose en los útimos tiempos, las emociones no son irreflexivas e irracionales, sino que, albergando un importante componente racional y reflexivo, permiten valorar objetos y situaciones y juzgarlos de acuerdo a esa valoración. Korsmeyer comulga plenamente con esta creencia (2011, pp. 20-24, 49-53).

22 En ese mismo sentido, afirma Adorno que el arte, el arte auténtico, sirve de expresión al «llanto al que le faltan las lágrimas» (Adorno 2004, p. 161).

23 Es lo que se infiere de la siguiente cita suya, escrita en su acostumbrado tono dialéctico: «Aunque se ve forzado a la negatividad absoluta, el arte no es absolutamente negativo gracias 
precisamente-dialécticamente, diríamos aquí- en tanto no placenteras, o sea, en tanto que el afecto que las sustenta es de los negativos, o para ser justos, de los considerados así, pues visto desde esta otra perspectiva, de negativos tendrían poco, por no decir nada. Es lo que explica que de un tiempo a esta parte vayan apareciendo nuevas denominaciones para referirse a esta clase de estados afectivos, a los que se califica, de manera bastante más ecuánime -y sin afán alguno de revanchismo, es preciso añadir ${ }^{24}-$, de difíciles (Korsmeyer 2014) e inusuales (Silvia 2009); pero en ningún caso ya de negativos, pues en verdad no lo son -no, al menos, en el segundo sentido propuesto aquí para este término-, tal y como se empeña en demostrar Korsmeyer, ${ }^{25}$ o sólo lo son desde la visión restringida e interesada de la experiencia estética que fomentó el dicurso estético moderno. Y si la vivencia del asco deviene valiosa y positiva, con ella se vuelve ineludiblemente también el arte que la procura, por molesto, doloroso o repulsivo que en un momento dado pueda parecer. De ahí que si el arte desagradable es considerado de más valor, hasta preferible en ocasiones, al agradable por el contenido de fondo que encierra -lo que implica entender, a su vez, que el tenido socialmente por «buen» arte puede llegar a doler, molestar, incluso repugnar (Smuts 2014)-, es porque el placer, las emociones positivas en general, sólo son una opción como otra cualquiera de la experiencia estética, pese a la hegemonía absoluta y la victoria que a lo largo de los dos últimos siglos se les han atribuido. Hasta podría hablarse de cierta tendencia a buscar este tipo de arte -que dejaría para siempre así su acostumbrada condición de perdedor- justamente por la experiencia poco grata que la acompaña. Es lo que sucede, ni más ni menos, con la representación del martirio de Cristo y de los santos del arte religioso cristiano, o también con el cine de Michael Haneke, al margen ya de la religión: todos son ejemplos de un arte poco confortable que por eso mismo resulta rico en otros aspectos, en

precisamente a esa negatividad» (Adorno 2004, p. 308).

24 De acuerdo en este sentido, una vez más, con el pensamiento estético de Rancière, que en lugar de pretender instituir una nueva jerarquía, aupando ahora a los vencidos y deponiendo a quienes fueron antes los vencedores, ha abogado en cambio por una nivelación sincera $y$, de ese modo, un juego armónico de relaciones entre unos y otros; es decir, se ha decantado por la igualdad, valor que aparte de desmentir los relatos de la modernidad y el modernismo levantados sobre el valor clásico de la libertad, permite tomar en consideración además las virtudes y potencialidades de los vencidos, hasta la fecha desatendidas; todo un programa, pues, de reconocimiento, más que de conquista (Infante del Rosal 2017), como es posible advertir, en cierta medida también, en Adorno y en Korsmeyer.

25 Algo que permite obtener un conocimiento que no puede ser obtenido de ninguna otra manera o por ningún otro procedimiento no puede ser nunca negativo, asegura la autora: «(...) but a 'painful' emotion cannot be considered negative if it is the only means by which one may understand something important» (Korsmeyer 2011, p. 172). 
capacidad reflexiva o conocimiento entre otras cosas, ausente muchas veces -más de las deseables- del arte simplemente deleitoso.

\section{LO NEGATIVO EN POSITIVO}

Es posible concluir, por tanto, que el arte y las afecciones dolorosas despertadas por él están lejos de mejorar nuestro bienestar; es un hecho universalmente constatable que no nos hacen sentir particularmente bien. Miradas con atención, hasta parece que lo perjudican: todos hemos comprobado también, alguna vez, cómo, de un modo u otro, nos desestabilizan emocionalmente. Pero ese no es motivo suficiente para deshacerse de ellas y enterrarlas, o para condenarlas a la ignonimia, al estatuto de malditas y proscritas -de negativas en nuestro segundo sentido-. Y no lo es porque al hacerlo, al perjudicar nuestro bienestar, al fastidiarnos, repugnarnos incluso como hemos visto, contribuyen también a engrandecer nuestras vidas y resultan así extraordinariamente positivas, pues nos permiten entender verdades importantes; verdades que recordándonos nuestro paso fugaz por la existencia como en el asco, igualándonos así a nuestros semejantes, nos conectan íntimamente con ellos, nos vuelven más humanos e incitan a trabajar de ese modo por un mundo mejor, por el negativo -dicho en términos de la negatividad dialéctica de Adorno y de nuestro primer sentido- del mundo de corte racionalista en el que vivimos y que tanto deja, sin embargo, que desear. Para lo que sí es motivo, en cambio, y mucho, es para volver la vista atrás y reescribir en términos incluyentes la historia que las excluyó, para poner en entredicho la verdad de ese gran relato que, obrando así, traicionó el ideal ilustrado de igualdad desde el que fue configurado. Esa traición es imputable a la mismísima estética moderna, que preocupada por definir subjetivamente los afectos, descuidó la obligación de hacerlo con todos, abriendo así un abismo infranqueable entre unos y otros que solo ahora empieza a remitir. Es ahora, ciertamente, cuando empiezan a descubrirse las conexiones y continuidades existentes entre las distintas emociones para las que antes no hubo lugar, el diálogo y la confrontación real, fruto de su interrelación verdaderamente dialéctica -ahora sí-, según esbozo y diseño contemporáneo de Adorno.

\section{REFERENCIAS BIBLIOGRÁFICAS}

ADORNO, Th. W. 2005 (1966): Dialéctica negativa. La jerga de la autenticidad, tr. A. Brotons Muñoz. Madrid: Akal, Obra Completa 6.

ADORNO, Th. W. 2006 (1951): Minima moralia: reflexiones desde la vida dañada, tr. J. Chamorro Mielque. Madrid: Akal, Obra Completa 4. 
ADORNO, Th. W. 2004 (1970): Teoría estética, tr. J. Navarro Pérez. Madrid: Akal, Obra Completa 7.

ÁLVAREZ LÓPEZ, P. 2000: Espacios de negación. El legado crítico de Adorno y Horkheimer. Madrid: Biblioteca Nueva.

BULLOUGH, E. 1957 (1912): «Aesthetic distance as a factor in art and an aesthetic principle», en Aesthetics. Lectures and essays, ed. Elizabeth M. Wilkinson, Stanford CA: Stanford University Press -reimpreso-.

BURKE, E. 2010 (1756): De lo sublime y de lo bello, tr. M. Gras Balaguer. Madrid: Alianza.

GALÉ ARGUDO, M. J. 2014: «Democracia y derechos humanos en la filosofía de Theodor W. Adorno», Bajo palabra. Revista de Filosofia, II, 9, pp 37-44 (https:// revistas.uam.es/bajopalabra/article/view/bp2014.9.003/71).

GÓMEZ, V. 1998: El pensamiento estético de Theodor W. Adorno. Madrid: Cátedra.

GUTIÉRREZ POZO, A. 2007: «Utopía en negro. El color negro en la estética negativa de Adorno y el arte radical contemporáneo», en Diego Romero de Solís, Jorge López Lloret e Inmaculada Murcia Serrano (eds.), Variaciones sobre el color. Sevilla: Secretariado de Publicaciones de la Universidad de Sevilla, 2007, pp. 187-208.

HORKHEIMER, M. y ADORNO, Th. W. 2001 (1947): Dialéctica de la Ilustración. Fragmentos filosóficos, tr. J. J. Sánchez. Madrid: Trotta.

INFANTE DEL ROSAL, F. 2017: «Jacques Rancière. Contra-historias estéticas», Daimon. Revista internacional de filosofía, 70, pp. 67-81 (http://dx.doi. org/10.6018/daimon/224791).

IRIONDO ARANGUREN, M. 2015: «Recordando a Adorno: estrategias narrativas y memoria de la violencia», en Aitor Aurrekoetxea y Fernando Golvano (eds.), Prismas críticos. Lecturas sobre Theodor W. Adorno. Granada: Comares, pp. 41-61.

KANT, I. 2001 (1790): Crítica del juicio, tr. M. García Morente. Madrid: EspasaCalpe.

KORSMEYER, C. 2014: "Curiosity and aversion in eighteenth-century British aesthetics», en Jerrold Levinson (ed.): Suffering art gladly. Londres: Palgrave MacMillan, pp. 45-67.

KORSMEYER, C. 2011: Savoring disgust. The foul and the fair in aesthetics. Oxford/ Nueva York: Oxford University Press.

LEVINSON, J. 2015 (2006): Contemplar el arte. Ensayos de estética, tr. F. Campillo. Madrid: Antonio Machado Libros, pp. 68-71.

MENKE, Ch. 2011: Estética y negatividad, tr. P. Storand y G. Leyva. Buenos Aires: Fondo de Cultura Económica.

MENKE, Ch. 1997 (1991): La soberanía del arte. La experiencia estética según Adorno y Derrida, tr. R. Sánchez Ortiz de Urbina. Madrid: Visor.

RANCIÈRE, J. 2014a (2011): Aisthesis. Escenas del régimen estético del arte, tr. M. 
Manrique y H. Marturet. Santander, Shangrila.

RANCIÈRE, J. 2104b (2000): El reparto de lo sensible. Estética y política, tr. M. Padró. Buenos Aires, Prometeo.

RANCIÈRE, J. 2005: Sobre politicas estéticas, tr. M. Arranz. Barcelona, Universitat Autònoma de Barcelona.

RETAMAL, Ch. 2016: «La melancolía de izquierda y el utopismo espectral», Pensamiento. Revista de investigación e información filosófica, 72, 271, pp. 371-393 (http://revistas.upcomillas.es/index.php/pensamiento/article/ view/6999/6806).

SILVIA, P. J. 2009: «Looking past pleasure: anger, confusion, disgust, pride, surprise and other unusual aesthetic emotions», Psychology of Aesthetics, Creativity and the Arts, 3, 1, pp. 48-51.

SMUTS, A. 2014: «Painful art and the limits of well-being», en Levinson Jerrold (ed.), Suffering art gladly. Londres: Palgrave MacMillan, pp. 123-152.

TAFALlA, M. 2003: Theodor W. Adorno. Una filosofia de la memoria. Barcelona: Herder.

VILAR, G. 2015: «La precariedad del arte. Adorno, telos del arte y reconciliación», en Aitor Aurrekoetxea y Fernando Golvano (eds.), Prismas críticos. Lecturas sobre Theodor W. Adorno. Granada: Comares, pp. 1-21.

ZAMORA, J. A. 2004: Th. W. Adorno. Pensar contra la barbarie. Madrid: Trotta.

María Jesús Godoy Domínguez es profesora Profesora Contratada Doctora del Departamento de Estética e Historia de la Filosofía de la Universidad de Sevilla.

Líneas de Investigación:

Estética contemporánea, Estética y cultura de masas, Estética de los afectos, Estética y género

Publicaciones recientes:

2017: «Midcult y arte de masas en la sociedad contemporánea», Daimon. Revista Internacional de Filosofía 70, pp. 115-129. http://dx.doi.org/10.6018/ daimon/226921.

2016: «La condición sacra del desacralizado arte contemporáneo», Aisthesis. Revista chilena de investigaciones estéticas 59, pp. 203-222. http://dx.doi.org/10.4067/ S0718-71812016000100012.

Correo electrónico: godoydom@us.es 